\title{
The challenges, approaches, and used techniques of CPS for manufacturing in Industry 4.0: a literature review
}

\author{
Baudouin Dafflon ${ }^{1} \cdot$ Nejib Moalla $^{2} \cdot$ Yacine Ouzrout $^{2}$
}

Received: 7 April 2020 / Accepted: 28 December 2020 / Published online: 17 February 2021

(C) The Author(s) 2021

\begin{abstract}
This work aims to review literature related to the latest cyber-physical systems (CPS) for manufacturing in the revolutionary Industry 4.0 for a comprehensive understanding of the challenges, approaches, and used techniques in this domain. Different published studies on CPS for manufacturing in Industry 4.0 paradigms through 2010 to 2019 were searched and summarized. We, then, analyzed the studies at a different granularity level inspecting the title, abstract, and full text to include in the prospective study list. Out of 626 primarily extracted relevant articles, we scrutinized 78 articles as the prospective studies on CPS for manufacturing in Industry 4.0. First, we analyzed the articles' context to identify the major components along with their associated fine-grained constituents of Industry 4.0. Then, we reviewed different studies through a number of synthesized matrices to narrate the challenges, approaches, and used techniques as the key-enablers of the CPS for manufacturing in Industry 4.0. Although the key technologies of Industry 4.0 are the CPS, Internet of Things (IoT), and Internet of Services (IoS), the human component (HC), cyber component (CC), physical component (PC), and their HC-CC, CC-PC, and HC-PC interfaces need to be standardized to achieve the success of Industry 4.0.
\end{abstract}

Keywords Industry 4.0 • Cyber-physical systems (CPS) • Internet of Things (IoT) • Internet of Services (IoS) · Manufacturing industry

\section{Introduction}

Due to the recent advancement of information and communication technology (ICT), machine-to-machine (M2M) communication, and wireless sensor network (WSN), new technologies such as cyber-physical systems (CPS), Internet of Things (IoT), and Internet of Services (IoS) are emerging to achieve effective automation and connected world. Eventually, the revolutionary concept of "Industrial Internet" [1,2] of US initiative and its German counterpart "Industrie 4.0" [3,4] evolves, drawing together

Baudouin Dafflon

baudouin.dafflon@univ-lyon.fr

Nejib Moalla

nejib.moalla@univ-lyon2.fr

Yacine Ouzrout

yacine.ouzrout@univ-lyon2.fr

1 University Lyon 1, DISP, F-69676, Bron, France

2 University Lyon 2, DISP, F-69676, Bron, France the CPS, IoT, and IoS [5-8] concepts. The initiative for Industry 4.0 proposes a highly networked and flexible ecosystem for the latest production control systems [9].

In recent years, industries have incorporated mobile, desktop, and web interfaces along with new multi-touch interaction modalities [10,11]. Interaction is a key idea to achieve interoperability [12] through multi-agent systems (MASs) [13, 14]. In addition, the "collaborative automation" paradigm [15] helps to achieve flexible, scalable, reconfigurable, interoperable, and network-enabled collaboration between dispersed embedded systems. These factors lead to a new dimension of industrial architecture with industrial CPS [16]. There are several projects SOCRADES [17], IMC-AESOP [18], GRACE [19], ARUM [20] etc. to address these issues. The key enabling technologies of the emerging industrial concept are CPS, IoT, and IoS.

The cyber-physical systems (CPS) is coined in 2006 [21] and defined as "cyber-physical systems are the integration of computation and physical processes. Embedded computers and networks monitor and control the physical processes, usually with feedback loops where physical processes affect computations and vice versa." [22]. It is identified as an 
influential research area by the US National Science Foundation (NSF) in 2008 [22, 23]. In the first-generation CPS, physical objects are equipped with identification technologies, while sensors and actuators are included in the second generation of CPS [24]. The latest third-generation CPS emerges in a feedback loop of sensing, physic modernization, decision-making, and evaluation of network compatibility. The principle of CPS is often characterized by "cyberizing the physical" and "physicalizing the cyber" [25]. The CPS is capable of handling large amounts of information integrated with adequate processes [6, 26, 27].

Internet of Things (IoT) $[28,29]$ enables an object to be connected with any other thing at any time and anywhere [30]. This, as an open system [31], connects many heterogeneous objects to the Internet, and it represents a worldwide network of interconnected entities [32, 33]. The concept of IoT in the industrial context is called the Industrial Internet of Things (IIoT) or Industry 4.0 [4, 34]. The Internet of Things (IoT) holds a great promise in handling the traceability and collecting end-of-use items [7, 35].

Furthermore, the Internet of Services (IoS) [36] comprises new service paradigms implemented through the service-oriented architecture (SOA) [37] or the RESTtechnology [38]. The IoS combines IoT to introduce the Internet of Things and Services (IoTS). The IoTS and CPS become the key-enablers to the vision of Industry 4.0.

The integration of CPS, IoT, and IoS envisions Industry 4.0 (I40), the fourth industrial revolution after the steam engine, conveyor belt, and programmable controllers [1], to facilitate the version of the smart factory [5, 39]. The six-sigma [5] outlines the principles Industry 4.0 implementation. Moreover, three-stage process model of Industry 4.0 includes envision, enable, and enact [40]. The CPS, IoT, and IoS in Industry 4.0 are interlinked [24], and we articulate this fact in Fig. 1.

CPS for manufacturing provides fault-adaptive control systems [41, 42] and manually created diagnosis models of the system's physics and operations [42-46] to achieve selfoptimization [47]. In spite of the great prospects of Industry $4.0,84 \%$ of the decision-makers reported that they are still not well informed about the chances and risks of Industry 4.0 [48]. This necessitates a narrative literature review to comprehend the new industry concept.

Study of the context of CPS for manufacturing is necessary, however, a formidable task in ICT and industrial manufacturing domain due to the outgrowth of many buzz words along with the rapid growth of contribution in this field. Therefore, our literature review on CPS for manufacturing in Industry 4.0 narrates the challenges, approaches, and techniques used in this domain for comprehensive understanding.

We searched relevant published articles on CPS for manufacturing in Industry 4.0 paradigm from 2010 to 2019. We analyzed the studies in the different levels of granularity, inspecting the title, abstract, and full text to include them into the prospective study list. We scrutinized 78 prospective studies out of 626, primarily extracted relevant articles through an online search on CPS for manufacturing
Fig. 1 CPS, IoT, and IoS in Industry 4.0

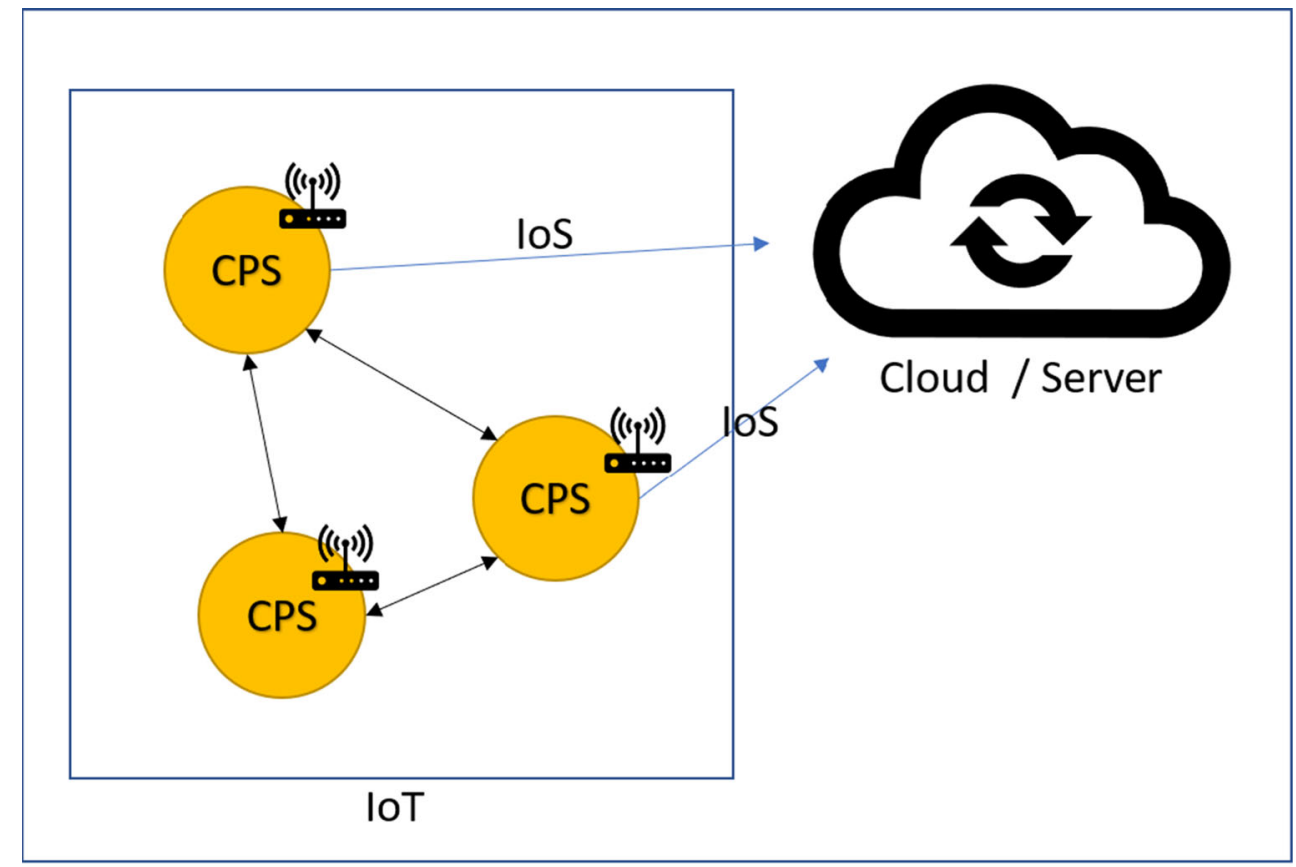

Industry 4.0 
Fig. 2 Nature of available content-volume in google scholar

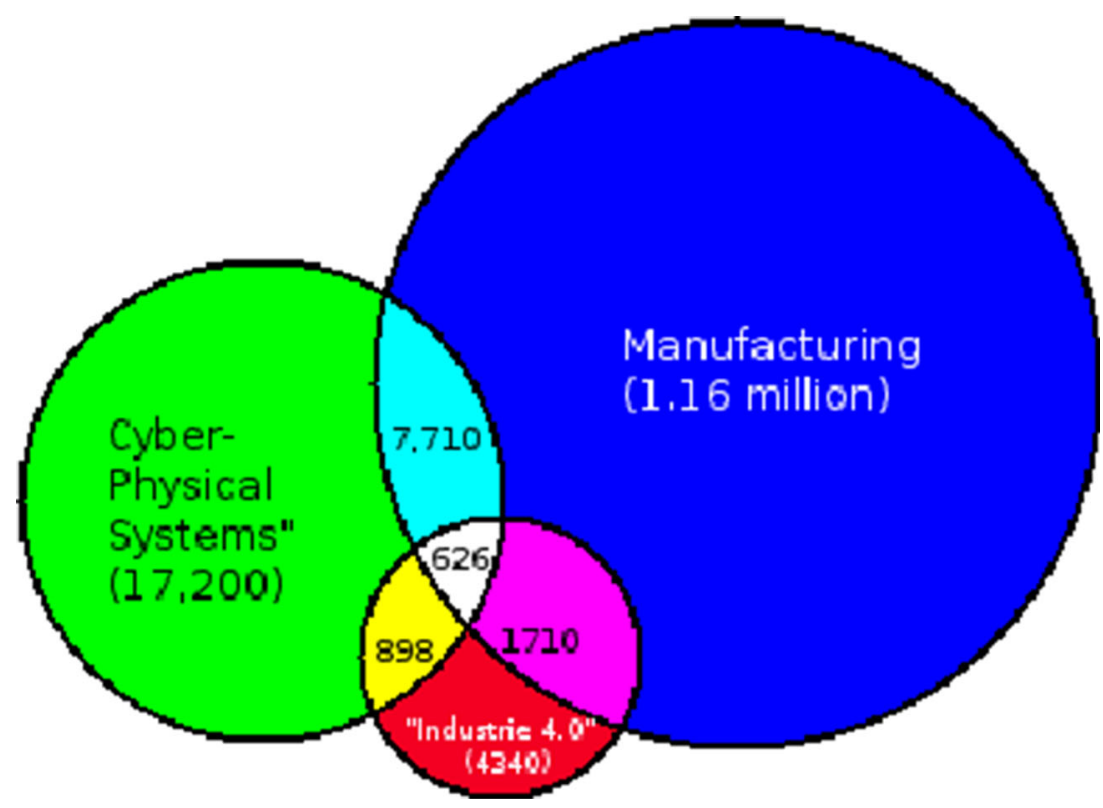

in Industry 4.0. First, we analyzed the context of the articles to identify the major components along with their associated fine-grained constituents of Industry 4.0. The human component ( $\mathrm{HC})$, the cyber component (CC), and the physical component (PC) are evident to be its major parts. Moreover, we found these three major components being capable of communicating with each other through their HC-CC, CC-PC, and HC-PC interfaces to form a workable integrated system. After the component identification, we reviewed different studies through a number of synthesized matrices to narrate the challenges, approaches, and stateof-the-art techniques from the component viewpoints for Industry $4.0 \mathrm{~s}$.

The rest of the paper is organized as follows. Section 2 adheres to the literature search, study selection, data extraction, and analysis. The major components along with their constituents of CPS for manufacturing are focused in Section 3, while Section 4 articulates the challenges beneath the forthcoming vision of CPS for manufacturing for Industry 4.0. Section 5 contains the approaches so far addressed in the reviewed materials, and the key technology enablers are portrayed in Section 6. Section 7 discusses some interesting contributions. Concluded remarks of our work are elaborated in Section 8.

\section{Materials and methods}

In manufacturing research domain, there are more than a million of contents indexed by google scholar ${ }^{1}$ since

\footnotetext{
${ }^{1}$ https://scholar.google.fr
}

2010. However, cyber-physical systems (CPS) and Industrie 4.0 are coined recently for integration, automation, and collaboration. Still, there are more than 17 thousand contents at google scholar on "Cyber-Physical Systems" and more than 4 thousand contents for "Industrie 4.0" from 2010 to 2019 . Due to the high volume of available contents and our interest in the recent technological paradigm shift in manufacturing, we adhere to be focused on our targeted keywords: "Cyber-Physical Systems" and manufacturing and "industry 4.0."

\subsection{Literature search}

We conducted a comprehensive search through google scholar for extracting literature on the revolutionary theme of "Cyber-Physical Systems" and "Industrie 4.0" for manufacturing from 2010 through 2019. During our search, we used the following keyword in google scholar: "Cyber-Physical Systems" and manufacturing and "industry 4.0." Moreover, we limited the duration by entering the range from 2010 through 2015 . We found 626 contents from the search in google scholar (See Fig. 2).

The distribution of the 626 contents over time reveals interesting findings. Figure 3 articulates the fact that the revolutionary "industry 4.0" and "Cyber-Physical Systems" in manufacturing have been addressed in a single paper in 2011. Eventually, the research in this field is getting researchers' attention with an exponential increase in number, and it became maximum in 2015. We already have 73 content in this field in 2019 so far. 
Fig. 3 Publication trend

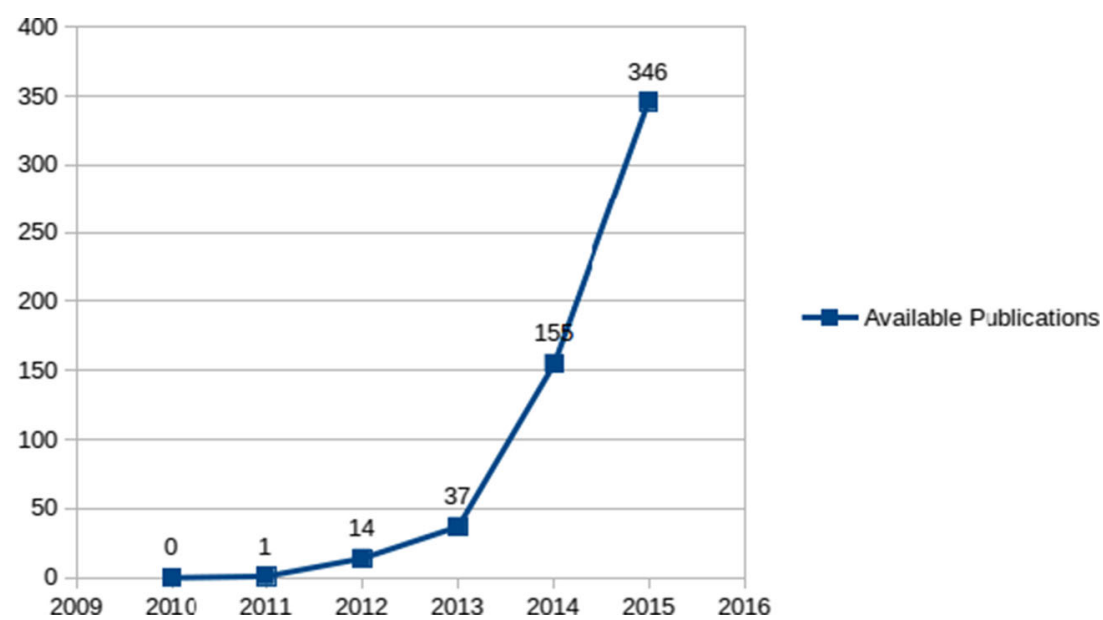

\subsection{Study selection}

We have carefully selected a number of potential articles from 626 initial contents of google scholar through three stages of the content evaluation process. In the first stage, 269 contents are eliminated due to their content nature such as survey, report, book or book chapter, and non-English contents. Then, 357 contents are primarily selected for abstract scrutinizing. In this second stage of abstract scrutinization, 155 contents are rejected due to the further identification of review, report, presentation, book or book chapter, non-technical, and non-significant contents. After the abstract scrutinization, full contents of 202 articles are extracted for further content analysis. In this elaborative third stage, 124 articles are excluded due to their less relevant, less significant, and less technical nature to "Cyber-Physical Systems," "Industrie 4.0," and manufacturing. Finally, we have selected 78 prospective studies for our review. The fact is portrayed in Fig. 4.

Among 78 of the selected studies for review, 36 articles are from journals, 31 papers from conferences, and 11 from workshop, symposium, and so on. Moreover, 5 articles of 2013, 15 articles of 2014, 46 of 2015, 12 articles of 2016, 10 of 2017, 43 of 2017, 11 of 2018, and 13 of 2019 have been selected for our review.

\section{Components of CPS for manufacturing}

The early dreams of control engineers to develop unmanned factories were abandoned not only due to ethical or social reasons but also mainly because of the engineering of such control systems proved to be unfeasible. Therefore, anthropocentric cyber-physical systems (ACPS) is considered as an important element for future manufacturing industry [49]. In the ACPS model, the authors proposed all connected physical component (PC), cyber component (CC), and human component (HC) in every individual level of operations. Another model addresses the connected CC and PC managed by humans [50]. After all, the context of CPS for manufacturing in Industry 4.0 can be observed in three influential components: (1) human component (HC), (2) cyber component (CC), and (3) physical component (PC). Moreover, the interfaces of HC-CC, CC-PC, and HC$\mathrm{PC}$ play an important role in connecting all components to become a unified system to attain a common goal. Figure 5 portrays the components of CPS in manufacturing.

searched 626 contents

(using google scholar)

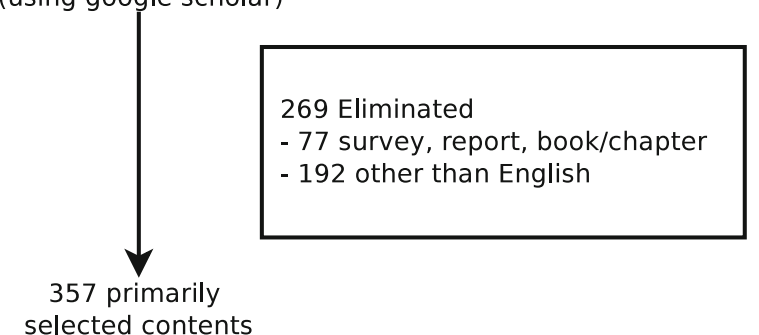

155 excluded at abstract-scrutinizing - review

- book/chapter/report/presentation

- non-technical/non-significant

202 articles

evaluated in detail

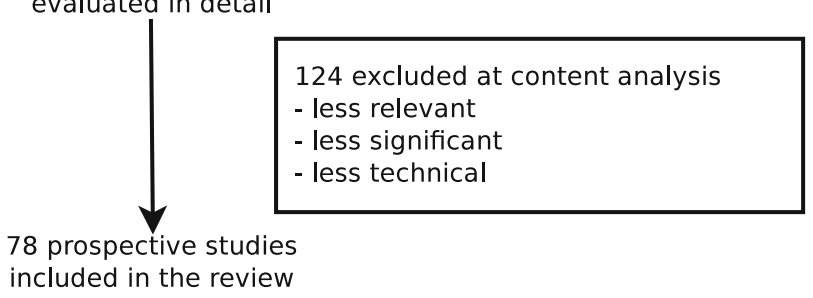

Fig. 4 Flow diagram for study selection 
Fig. 5 Inter-linked human component (HC), cyber component (CC), and physical component (PC) of CPS for manufacturing industry

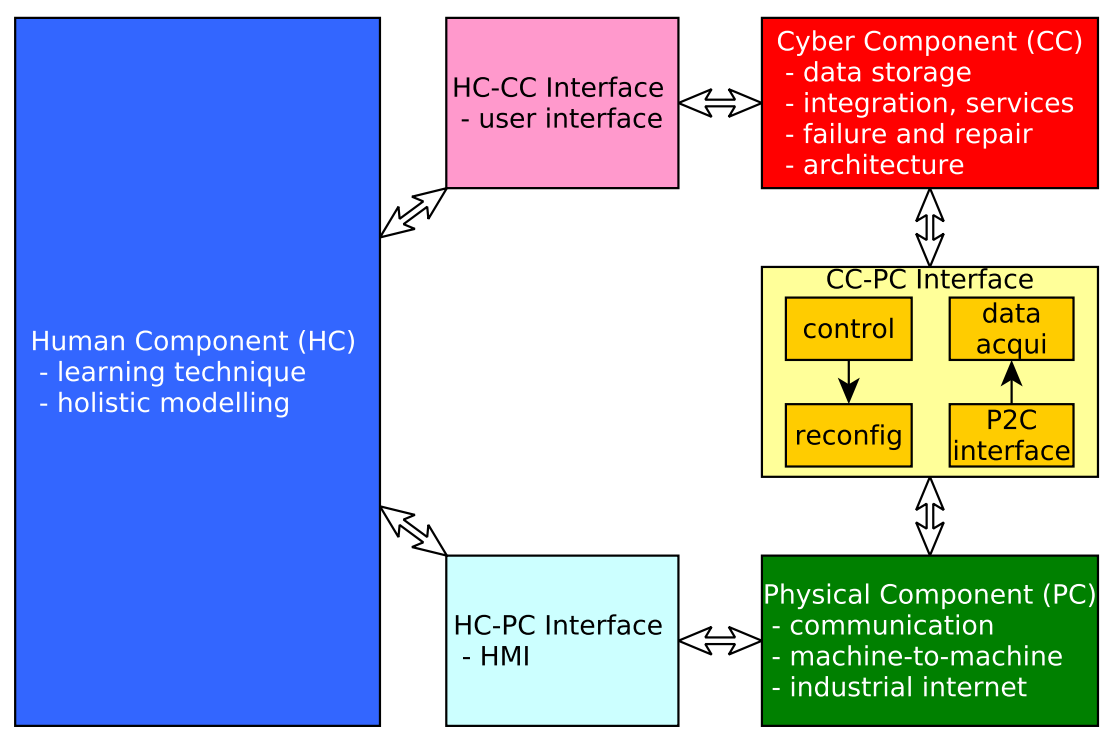

\subsection{Human component}

Due to the increasing demands of customers for customized products and the rapid changes in machinery/systems of CPS-based manufacturing in Industry 4.0, the production process needs a shorter product life cycle, personalized products, and quick employee adaptation to the newly innovative changes. Human is considered as one of the inevitable components for the newly coined Industry 4.0 to be successful, and this component is called as Human component (HC). Different articles focus on the HC constituents like holistic production model or anthropocentric processes and learning techniques to adapt employee to the rapidly changed machinery/systems in the manufacturing industry. Table 1 articulates different constituents of $\mathrm{HC}$ that are associated with the analyzed source articles.

Learning techniques The replacement of the traditional components by dynamic and intelligent CPS demands the broader skill of human production workers. Therefore, quicker learning techniques for workers become essential [51, 52]. Industry 4.0 supports work-based learning [53] and an augmented reality (AR)-based interactive instruction manuals [54] for a quicker understanding of changes in production.

Table 1 Different constituents of human component (HC) that are associated with the analyzed source articles

\begin{tabular}{ll}
\hline Constituent & Sources \\
\hline Learning technique & {$[51-54]$} \\
Holistic model & {$[49,55-57]$}
\end{tabular}

Anthropocentric model In an anthropocentric cyberphysical systems (ACPS) for the future manufacturing industry, human component (HC) is shown as an essential element [49]. The holistic or human model comprises of the cloud-assisted service-oriented architecture [55], or a human-centered modeling approach on generic coordination [56] to enable CPSs to integrate human intelligence.

\subsection{Cyber component}

Cyber is another important component of CPS for manufacturing in Industry 4.0 that uses computing devices as important processing tools. Different articles focus on the CC constituents like data storage, data management and services, failure and repair management for dynamic reconfiguration, and overall cyber architecture. Table 2 articulates different constituents of $\mathrm{CC}$ that are associated with the analyzed source articles.

Data storage A federative, secure, and cloud-based Virtual Fort Knox platform [58], cloud-integrated CPS

Table 2 Different constituents of cyber component (CC) that are associated with the analyzed source articles

\begin{tabular}{ll}
\hline Constituent & Sources \\
\hline Data storage & {$[58-60]$} \\
Data management and services & {$[58,60-68]$} \\
Failure management & {$[55,69]$} \\
Repair management & {$[24,70,71]$} \\
CC architecture & {$[61,72-87]$} \\
\hline
\end{tabular}


(CCPS) [59], and cloud-assisted service-oriented architecture (SOA) [60] are used for efficient data storage in collaborative processing.

Data management and services The three-stage model for optimization of production system [63] and sustainable production systems [67] have been used for data integration. The machine learning technique into CPS can bring self-predict capabilities [62], whereas industrial softwareproduct-service systems (ISPS) in a value chain [64], Sense-Compute-Control (SCC) applications [65], and new standard architectures for industrial networks and middleware [66] are popular services.

Failure management Failure management has always been crucial to seamless serial operations. An intelligent ramp-up assistant module [69] and embedded model-based advanced production control [55] are used for failure management.

Repair management Repair management comprises the adaptive repair process chain for manufacturing [70], intelligent predictive maintenance (IPdM) system for reaching zero-defect manufacturing (ZDM) [24], and cloudbased framework for lean MRO of the equipment [71].

CC architecture There is a number of cyber component architectures that focus on manufacturing Internet of Things with layered technologies [74], plant engineering [76], monitoring and diagnosis of cyber-physical systems [80], organizing and locating services [81], lifecycle model of cyber-physical systems in inter-organizational value networks [84], and advanced planning systems (APS) [86]. Multiagent system (MAS) architecture has been introduced in the holonic concept of manufacturing [72], GRACE multi-agent system for integrating process and quality control [78, 79], and vertical integration using MAS technology in reconfigurable manufacturing system [87]. A new production quality paradigm for modern, zero-defect oriented manufacturing industries [75] and knowledgebased layered and intelligent systems for Industrie 4.0 [85] have been introduced. Moreover, digital description of future production system [61], intelligent manufacturing using CCPS for complex industrial applications (CIA) [73], multiple resolution models of a manufacturing cell [77], and supervisory control and data acquisition (SCADA) systems [82] also, describe cyber component architectures.

\subsection{Physical component}

Physical component (PC) is the lower level hardware part of CPS component for manufacturing that uses physical or hardware as a technology component. Different articles
Table 3 Different constituents of physical component (PC) that are associated with the analyzed source articles

\begin{tabular}{ll}
\hline Constituent & Sources \\
\hline Communication & {$[88-90]$} \\
M2M interaction & {$[54,91-93]$} \\
\hline
\end{tabular}

focus on PC constituents like communication and machineto-machine (M2M) interaction. Table 3 articulates different constituents of PC that are associated with the analyzed source articles.

Communication Communication among constituents of physical components is imminent. Cyber-physical sensor system (CPSS) in industrial application [94], secure hardware module [88], and control automation systems [89] address communication context.

M2M interaction Other than communication, machine-tomachine (M2M) interaction is important in integrated manufacturing using CPS. Industrial cyber-physical systems for two robots interaction inline assembly using smart space infrastructure based on Smart-M3 (Multi-vendor, Multi-device, and Multi-part) [93] and interaction behaviors among industrial equipment [91] focus on M2M interaction.

\subsection{Interfaces}

Different major components (HC, CC, and PC) are often integrated through HC-CC, CC-PC, and HC-PC interfaces. The analyzed source articles are depicted in Table 4.

\subsubsection{HC-CC interface}

User interface The user interface usually plays an important role in bridging human and cyber components. An interface to CC for self-organized scheduling of labor times in production provides flexible labor utilization [99]. Administrative shells of Industry 4.0 [95], subject-oriented suggestions for re-design of factory (SURF) workplaces [96], visual computing of ICT solutions in manufacturing [97],

Table 4 Different constituents of interfaces that are associated with the analyzed source articles

\begin{tabular}{lll}
\hline Level & Constituent & Sources \\
\hline HC-CC & User interface & {$[49,95-100]$} \\
CC-PC & Data acquisition & {$[83,101-105]$} \\
& Hardware control & {$[24,68,106-111]$} \\
& Reconfiguration & {$[107,112-117]$} \\
& Physical-to-cyber interface & {$[50,118,119]$} \\
HC-PC & Human-machine interface & {$[49,97,110,120-123]$}
\end{tabular}


business model-based cyber-physical production systems (CPPS) in a value chain [98], and a UML profile for IoT (UML4IoT) [100], are named a few to address user interfaces.

\subsubsection{CC-PC interface}

Data acquisition In data acquisition, data processing requirements have been analyzed for Industry 4.0 [103]. Semantically enabled plug-and-produce [102] and RDF transformation of AutomationML for automated classification of the technical specification [105] play a vital role in data acquisition. Delay-aware mobile wireless sensor network (MWSN) routing protocol [101] and enterprise sensing establishment [104] are also used for this purpose in Industry 4.0.

Hardware control In the seamless component integration, cyber component controls physical components using software automation for cyber-physical production systems (CPPS) [108], the simulation-based optimization in (near) real-time [109], the decentralized self-configuring production control architecture using configuration and information memory (CMory) [107], and software design for cyber-physical automation systems [111].

Reconfiguration The intuitive robot programming for production industry [113], robot configuration and programming autonomously [114], model separation diagnosis of cyber-physical production Systems (CPPS) [116], and reconfigurable smart factory architecture [117] are a few important cyber components to address reconfigurable physical components.

Physical-to-cyber interface Physical-to-cyber interface plays an important role in integrating physical components to cyber components through data communication. We have found different physical-to-cyber interface components, namely data on an RFID transponder attached to different elements [118], CPS for industrial automation systems (IAS) [50], and traceability and tracking in the automotive domain [119].

\subsubsection{HC-PC interface}

Human-machine interface (HMI) Human-machine interface (HMI) is eminent in HC and PC integration. HMI and data exchange between all modules for machine-to-machine (M2M) and machine-to-human (M2H) communications in production processes are well managed by a workflow manager (WFM) [110]. Smart glass-based wearable technologies support operators' activities in a CPS manufacturing environment $[120,121]$. Moreover, hand-held mobile devices, head-mounted display (HMD), and user-contextaware services using a model-view-controller environment (MVCE) plays an important role in interfaces [121]. Nevertheless, the self-optimization mechatronics [122] and the social robotics and human-computer interaction (HCI) with tangible user interface (TUI) [123] are a few examples of HMI.

\section{Challenges to CPS for manufacturing}

The challenges to CPS for manufacturing can be observed from four viewpoints: improve production, dynamic reconfiguration, standardization, and information technology. Improve production includes the factors of quality control, productivity, visualization, monitoring, production time, cost, PLC, zero defect, safety, risk, and improve automation. Sensor network, process, machines, workers, failure and repair management, flexibility, and customer-centric product configuration are part of dynamic reconfiguration. Moreover, IT focuses on semantics, multilingual, interoperability, security, global data sharing, data integration, sustainability, augmented reality, cloud and so on.

The primary concern of using CPS in manufacturing is to produce improved product shortening production time. In this regard, automation and process/machine reconfiguration are to be ensured dynamically satisfying a common standard. Furthermore, information technology plays to a seamless integration of all components. Different articles, which are associated with major components (HC, $\mathrm{CC}$, and PC), are reviewed to identify the current or forthcoming challenges. The analyzed source articles are articulated in Table 5.

\subsection{Improve production}

Even a performing CPS may fail if no human uses it due to the unsatisfied design, or sudden changes in customer requirements. Therefore, customer integration with the system becomes an important challenge to design a functional CPS [56] to cope with the volatile market demand [99]. Flexible and reconfigurable production systems $[51,110]$ and effective human-machine interaction to reduce the time and cost of machine control and maintenance [120] is always inevitable. This, in turn, brings forth the issue of employee adaptation to the new technology [51, 53, 124].

In Industry 4.0, real-time data acquisition, storage, and data analysis using machine learning techniques [80] become formidable tasks. Moreover, uncertainties in the quality and volume of product return [63] become an unavoidable issue. It requires effective data and storage management for "intelligent monitoring" and 
Table 5 Reviewed article distribution in terms of "component" vs. "challenges"

\begin{tabular}{lllll}
\hline Component domain & Improved product & Dynamic reconfiguration & Standardization & Information technology \\
\hline Human (HC) & {$[51,53,56,99]$,} & - & {$[50]$} & {$[49,52,54,55]$} \\
Cyber (CC) & {$[110,120,121]$} & & & {$[71,75-77]$} \\
& {$[24,59,60,63,67]$} & {$[58,66,69,70,74]$} & & {$[65,73,85,86]$} \\
& {$[72,78,79,111]$} & {$[81,84,87,96]$} & {$[102-105,109]$} \\
Physic (PC) & {$[50,91,119]$} & {$[101,108]$} & - & {$[95]$} \\
& & {$[88,89,93,94,113]$} & & \\
\hline
\end{tabular}

"intelligent control" [60] and increases collaboration in productivity [67]. In this connection, many researchers are moving towards cloud management. In turn, this imposes 3 challenges: virtualizing resource management, scheduling of cloud resources, and life cycle management (LCM) [59].

Improve production also depends on the seamless data flow from physical components to cyber components. Physical-to-cyber interface processes history, traceability, and tracking to rectify processing defects and product recalls. It needs more than just using off-the-shelf RFID systems [119]. Furthermore, formal methods become formidable issues to specify and verify machine-to-machine interaction behaviors among industrial equipment [91]. s. Physical-to-cyber interface processes history, traceability, and tracking to rectify processing defects and product recalls. It needs more than just using off-the-shelf RFID systems [119]. Furthermore, formal methods become formidable issues to specify and verify machine-to-machine interaction behaviors among industrial equipment [91].

\subsection{Dynamic reconfiguration}

Worldwide markets require a new modular, flexible, adaptive, and reconfigurable manufacturing [72, 78, 79] for on-demand and personalized products [81, 117]. A key driver to the flexibility is the introduction to an industrial robot, which needs to be easily programmable [113]. Growing uncertainty of product-life-cycles, increasing product variance, and globalization demand robot configuration, and time minimization [114]. However, fabrication of industrial robots [123] and the integration of self-optimization in mechatronic systems [122] are challenging tasks. The evolution from computer integrated manufacturing (CIM) to Industry 4.0 requires human-machine interface and machine-to-machine interaction through smart space infrastructure [93]. This revolutionary Industry 4.0 demands novel intelligent sensors and sensor system with increased flexibility and adaptability [94] along with their networking capability. A secure, robust, and fast network is an essential issue for industrial applications [101] for successful horizontal integration. Intelligent and cooperative networking [58] or dynamic enterprise networking [84] is required for future automated manufacturing. Cryptographic authentication and a secure storage are also important issues in the automated factory [88] to avoid any deception. In addition, identification of anomalous system behavior and deduction of the underlying root cause [116] is a necessary, however, formidable task.

The proliferation of advanced interaction models and flexible industrial plants demands strategies for software deployment in automation [89]. The increased data availability over the life cycle of machine tool components requires physical-to-cyber interface [118] that adheres to sending data from machine tool to the middleware. The development of a new and flexible industry oriented middleware to address volatile market becomes a challenging task [66].

Volatile market demands the up-gradation of the traditional manufacturing into operational framework [74], which has the ability to enable a fast modification and system-change, in order to fulfill quickly changing market needs [61]. Vertical integration of various components inside a factory to implement a flexible and reconfigurable manufacturing system is one of the challenges, however, key features of Industry 4.0 [87]. Dynamic reconfiguration requires a more advanced approach to merging different processes and specific dynamic products with quality monitoring, fault detection, and assistance system to ensure a seamless workflow to achieve maximum productivity [106]. The new product ramp-up often causes different unpredicted failures that demand formidable failure management system in order to guarantee the planned time-to-market [69]. Whenever a failure is detected, repair becomes an inevitable task for ensuring long-lived products, long lifecycles, reducing high MRO costs [71]. New automation and a high degree of flexibility in a repair of high-value parts require a substantial amount of manual preparation for repair process chain [70], which is a bottleneck to success. After all, a value chain risk assessment [98] is an important issue. 


\subsection{Standardization}

CPS for manufacturing is an emerging technology in the industry. Therefore, it requires standardization. A few articles address the challenges of standardization and seamless process integration [76], seamless data aggregation and disaggregation [77], standardization compliance [95], and product-service innovation, product variety, quality standards, support services, and immediacy or order satisfaction [75]. Industrial automation systems (IASs) are commonly developed using the de-facto standard IEC 61131 [50]. Although version 2.0 of IEC 61131 is introduced to address the new challenges of complex industrial automation (CIA) systems, the standard IEC 61499 has been defined to eliminate limitation of IEC 61131. However, we need more and more work on standardization for maturing this new emerging technology.

\subsection{Information technology}

Information technology (IT) is an important part of CPS for manufacturing. This viewpoint classifies the key challenges into two types: human-centred and cyber-centred.

Human-centered The solutions used so far to control and optimize production are incapable of solving existing problems. It requires holistic production control (HPC) [55]. Human-centric IT development requires to succeeding the emerging CPS for manufacturing in Industry 4.0 [49]. Due to the personalized product and new modular, flexible, adaptive, and reconfigurable manufacturing paradigm, the smart space infrastructure changes quickly. Therefore, the factory often requires broader skills of a human worker to understand and manage diverse interrelation between a physical object and digital counterparts [52]. In addition, a rapid learning technique based on augmented reality (AR) is becoming important; this type of technique is essential for the assembly, control, and maintenance of machines [54].

Cyber-centered IT-based user interface becomes inevitable to the adaptation of Internet of Things (IoT), cloud computing, service-oriented architectures (SOA), and mobile computing [100]. The challenge to Industry 4.0 is to enable smart industrial devices to communicate and understand each other. This requires a digital representation of all information (and services) about and from a physical manufacturing component [95]. Model driving software engineering (MDSE) methodology for developing sensecompute-control (SCC) applications [65], software-enabled hybrid solution [64], and sensing enterprise vision [104] become key challenging architectures in cyber component (CC). Moreover, data integration exhibits the necessities of the machine-readable semantic formalization [102] to convert the AutomationML [105], to integrate APS to ERP [86]. In Industry 4.0, systems require to decide and trigger actions, and control each other independently [85]. Moreover, newly adopted Internet technology becomes a challenge in automation [82]. Furthermore, (near) real-time optimization to control hardware through the use of cyber components is essential, but it is a considerable task. [109, 125].

\section{CPS approaches for manufacturing}

One of the key investigations of our review work is to find out the different approaches used to comply CPS in manufacturing for Industry 4.0. The approaches to CPS for manufacturing can be observed from three viewpoints: sensor-based, data-driven, and CPS oriented software approaches. The primary concern of sensor-based approach is to identify the data sharing capabilities and real-time routing, whereas data-driven approaches come from the semantic knowledge-based digital representation and cognitive approach. Moreover, CPS-oriented software approaches are derived from the terms patterns, IoTenabled, dynamic reconfiguration, multi-agent systems (MAS), human-machine interaction (HMI), and so on. Different articles associated with major components (HC, $\mathrm{CC}$, and PC) are reviewed to identify the current or forthcoming approaches from the identified viewpoints, which are articulated in Table 6.

\subsection{CPS-oriented software approaches}

\subsubsection{Software approaches in Human Component}

The anthropocentric software interface plays an important role in envisioning CPS for manufacturing.

A UML model for the development of industrial automation systems (IASs) [50] and service-oriented architecture (SOA) become essential for anthropocentric cyber-physical systems (ACPS) as a reference model. This model can integrate the PC, CC, and HC for factory automation [49]. Personal planning and scheduling approaches monitor the order backlog in a production environment and estimate the actual workload [99] to maximum utilization of labor time. Moreover, workflow manager (WFM), human-machine interface (HMI) is considered the central module of modular production system (MPS) architecture [110]. Different related technology can be used for a set of interactions between human and machine through designing a new user interface approaches [120,121]. Nevertheless, a mixed-reality-based learning environment approach becomes necessary for the adaptation of a broader skill of human workers into future factories. It combines physical objects and visualization of 
Table 6 Reviewed article distribution in terms of "component" vs. "approaches"

\begin{tabular}{llll}
\hline Component approaches & Sensor-based & Data-driven & CPS-oriented software \\
\hline Human (HC) & - & {$[51,53,55-57]$} & {$[49,52,54,99]$} \\
Cyber (CC) & {$[61,63,84,101]$} & {$[24,70,72-77]$} & {$[110,120,121]$} \\
& & {$[80,85,102-105,109]$} & {$[71,78,79,81,82,86,87]$} \\
Physic (PC) & {$[88,89,93,113]$} & - & {$[96-98,100,108,111]$} \\
& {$[114,118,122,123]$} & & {$[91,116,117,119]$} \\
\hline
\end{tabular}

its digital content through augmented reality (AR) [52]. In addition, Holobuilder is developed to be a new horizontal surface for the artifact of instructional education manuals in Industry 4.0 [54].

\subsubsection{Software approaches in cyber component}

User interface (UI) is an important part of cyber component (CC) to integrate other components, i.e., $\mathrm{HC}$ and PC, in CPS for manufacturing. A pattern-based business model [98] keeps track of different risks and changes in a production environment, production resources, and production processes of cyber-physical production systems (CPPS). An approach, called as UML4IoT (a UML profile for IoT), supports the automatic generation of the IoTcompliant interface of the mechatronic components [100]. Meta-process [96] improves the involvement of all stakeholders in the smart factory. In the manufacturing industry, visual computing services become inevitable in the Industrial Internet [97].

A software engineering approach is introduced for the characterization of advanced planning systems (APS) [86], whereas agent-based approaches [78, 79, 82, 87] are used for intelligent negotiation and integration of resources. Moreover, a domain-oriented and location-based federated architecture is articulated in [81, 126, 127] using the semantic web and distributed hashtable-based peerto-peer for organizing and locating services to the Industry 4.0.

Data integration through four enablers (IT globalization, single source of truth, cooperation, and automation) increases collaboration in production systems [67]. To support enablers, cloud technology becomes inevitable for storage, integration, and services [58-60]. The industrial software-product-service (ISPS) system enables CPS as a software-enabled hybrid solution to the customization and integration of products and services in a value chain [64]. The model-driven software engineering (MDSE) methodology transforms a new sense-compute-control
(SCC) applications for the Internet of Things and Services (IoTS) from domain-specific modeling (DSM) as a service [65].

According to agendas of Industry 4.0, a plant should be adapted to the changes automatically. Hardware control, automatic failure, and repair management are important issues. CPS-tool-based holistic failure management [69] system can solve the different options of failure modes. The closed-loop PLM information management system can effectively manage the process of maintenance, repair, and overhaul (MRO) life cycle [71]. Moreover, a CPPSenabled automation software development approach has been introduced [108]. Hardware can be control by its invariant properties through the way of modifications to existing IEC 61499 FB syntax using the time stamped events $[111,128]$.

\subsubsection{Software approaches for physical component}

Physical-to-cyber interface plays an important role to glue PC and CC effectively. End-users are interested in implementing automatic identification systems, a removable and reusable smart RFID bolt in machinery is presented [119]. Physical component reconfiguration is an important part of CPS for manufacturing. Model-based diagnosis deals synchronization between system and model for fast-changing in CPPS [116]. An app-based modular software approach for a generic and manufacturingindependent reference architecture, consisting of the principal components as CPS, device registry, industrial app, and mobile user interface, is proposed to enable dynamic reconfiguration of intelligent devices through the usage of modular software applications [117]. Furthermore, software approaches for M2M interaction ensure the integration and interaction of industrial equipment to envision the proposed industrial automation. All equipment is a kind of critical system in respect of security and safety. The integrated framework has been introduced through $\pi$-calculus [91]. 


\subsection{Data-driven approaches of CPS for manufacturing}

Data-driven approaches are important to CPS for manufacturing. They are distributed over holistic, cyber, and physical components.

\subsubsection{Holistic data-driven approaches}

Holistic data-driven approaches include different approaches such as decision-support reasoning, messageoriented middleware (MOM) infrastructure, neural network modeling, fuzzy modeling, and model predictive control (MPC) were developed to support the concept of holistic production control (HPC) [55]. These approaches turn the classical CPSs towards human-centered CPSs [56]. Group-based and activity-oriented scenarios [51], ramp-up processes, and instructions [53] enable the employees to learn into practice within their professional environment. Moreover, a combination of only successful holistic lean production of computer integrated manufacturing (CIM) and classical automation technology, also called Lean Automation, facilitates an automated decentralized production control [57].

\subsubsection{Cyber data-driven approaches}

UML source code level specification [100] and semantic I4.0 component-based approach to develop a semantic knowledge-based digital representation by RDF, RDF Schema, and OWL [95] are presented in a user interface to integrate cyber-physical, cyber and human components, and IoT.

In the cyber-physics interface, data acquisition from the machine and sensors of the physical component becomes important for further analysis in the cybernetic component. Ontological classification and reasoning, transforming AutomationML into RDF [105], I4.0-Services [102] becomes important data-driven approaches. Nevertheless, "sensory" processing translates raw data into actionable decision [104].

Cyber approaches are often used to control hardware. Intelligent predictive maintenance (IPdM) system is used to reach zero-defect manufacturing (ZDM) [24]. A simulationbased approach analyzes information transmitted from devices [109]. Moreover, repairing features and function blocks together are applied in adaptive repair process chain [70].

There are a number of cyber architectures that address holonic concept for controlling and monitoring of the individual activities multi-agent system (MAS) [72], function-based engineering [76], cognitive solution for the analysis of CPS [80], effective tracking of dynamic manufacturing process with active real-time data acquisition [74], instruction domain-based cognitive approach to the modeling of electronic data analysis of CNC machine tool workprocess [73], a new production quality paradigm for zerodefect oriented manufacturing relying on a strong interaction among production components [75], investigation of the potential applications of "Big Data" techniques in PLM [129], and multi-resolution (process, machine, and manufacturing cell level) modeling in the virtual factory [77, 130]. All of these different data-driven architectures have been used in the cyber component.

Moreover, the article [85] focuses on a model, consisting of holistic, semantic, and physical layers to collect signals from sensors and actuators through a data bus. Then, the collected asynchronous data is aligned and synchronized at the standardization layer before feeding into semantically enhanced CPS layer through communication layer. In the semantically enhanced CPS layer, knowledge manager uses a reasoner that utilizes IN/OUT for pulling or pushing data streams and semi-automatic rules by domain experts extracted from BIS, ERP, and PLM. Lastly, the application layer contains human-machine interaction modules.

\subsubsection{Physical data-driven approach}

The physical data-driven approach addresses the horizontal automation by PLC and the intelligent chunk integration in the vertical hierarchy through the use of OPC UA (OLE for process control unified architecture) [94].

\subsection{Sensor in CPS for manufacturing}

An inevitable part of CPS is a smart sensor that produces interesting data to be further used in decisionmaking system and to control actuators. In an enterprise, a secure, robust, and near-real-time communication network is essential for data acquisition. To achieve this vision, a delay-aware mobile WSN routing algorithm (MWSN) approach has been proposed [101]. The CPS-based collaborative industrial process requires a horizontal connection to value network in real-time using holistic life cycle concept taking network structure changes, new hardware, new/reconfigured software, and changing market needs into accounts [84]. In spite of fast modification, and system changes, the task-oriented programming for assembly systems is used for modeling of resources, processes, and products $[61,131]$ in order to fulfill quick marketing requirement changes. 
A sensor as a physical component introduces industrial robots to cope with different variations of tasks that can be configured by using robot language efficiently [113]. Plug and Produce become an important approach for reconfiguration of modular robot cells [114]. In the industrial communication and integration, a RFID transponder is attached to the component to store data [118] and to achieve interoperability including a migration path [89]. Moreover, a secure near field communication (NFC)-enabled hardware module is used to local identification helping to prevent device impersonation attacks, device clones and human errors on device identification in the host controller and the ID module [88]. In addition, in the reference model of M2M interaction, robots interact and coordinate their activities in smart space based on the Smart-M3 platform [93]. Nevertheless, methods for the tangible user interface of social robotics [123] and self-optimization in mechatronic systems [122] are proposed.

\section{State-of-the-art techniques for CPS in manufacturing}

In the realm of manufacturing, CPS comprises smart machines, storage systems, and production facilities capable of autonomously exchanging information, triggering actions and controlling each other independently. This technological evolution in the industrial revolution will transform value chains and will lead to the emergence of new business models. Value chain includes programmable logic controller (PLC) and horizontal and vertical integration. The technological development comprises data-driven, model-based, interaction, and semantic-driven techniques. Cloud and localized servers are few to name as virtualization technologies in general.

Table 7 at-a-glance articulates several enabling state-ofthe-art techniques used in diverse systems to cope with the

Table 7 Different state-of-the-art techniques addressed in Industry 4.0

\begin{tabular}{|c|c|c|}
\hline Component & Domain & Used techniques \\
\hline \multirow[t]{2}{*}{$\mathrm{HC}$} & $\begin{array}{l}\text { Learning } \\
\text { technique }\end{array}$ & $\begin{array}{l}\text { Logistic learning factory (LLF) [51], work-based learning [53], augmented reality } \\
\text { (AR) }[52,54]\end{array}$ \\
\hline & modeling & $\begin{array}{l}\text { Holistic production control (HPC) [55], autogenetic and conversation model [56], } \\
\text { lean automation [57], semantic web-based mobile interaction [49] }\end{array}$ \\
\hline HC-CC interface & User interface & $\begin{array}{l}\text { Reference architecture model for Industry } 4.0 \text { (RAMI 4.0) and SPARQL [95], } \\
\text { Mobile communication }[49,99] \text {, web-based interface [98], LW M2M, and datagram } \\
\text { security [100] }\end{array}$ \\
\hline \multirow[t]{4}{*}{$\mathrm{CC}$} & Data storage & $\begin{array}{l}\text { Microdatabase [132], federative community cloud [58], cloud-based schedul- } \\
\text { ing [59], IaaS, PaaS, and SaaS using cloud [60] }\end{array}$ \\
\hline & Data management and services & $\begin{array}{l}\text { AutomationML, SysML and UML [61], naive Bayes classifiers [62], particle } \\
\text { swarm optimization (PSO) [63], service integrator [58], model-driven software } \\
\text { engineering [65], virtual engineering of value chain [67], IaaS, PaaS, SaaS [68] }\end{array}$ \\
\hline & Architecture & $\begin{array}{l}\text { Multi-agent system (MAS) [72, 77-79, 83, 87], multi-criteria decision-making } \\
\text { framework [75], direct web remoting (DWR) framework [82], semantic architec- } \\
\text { ture [85], SEBoK, and SQuaRE model [86] }\end{array}$ \\
\hline & Failure and repair management & $\begin{array}{l}\text { Intelligent ramp-up assistant [69], agent-based closed-loop repair process } \\
\text { chain [70], data mining technique [24] }\end{array}$ \\
\hline \multirow[t]{4}{*}{ CC-PC interface } & Data acquisition & Semantic modeling [83, 102, 104, 105], SCADA [83] \\
\hline & Hardware control & $\begin{array}{l}\text { Digital object memory (DOMe) [106], CIMory [107, 110], timestamp in } \\
\text { communication [111], RFID [24, 68] }\end{array}$ \\
\hline & Reconfiguration & $\begin{array}{l}\text { Operator controller module (OCM) [112], CIMory and workflow manager } \\
\text { (WFM) [107], robot [113, 114], SEFU/IFU [115], web-socket messaging [117] }\end{array}$ \\
\hline & Physical-to-cyber interface & DataMatrixHF or UHF [119] \\
\hline \multirow[t]{2}{*}{$\mathrm{PC}$} & communication & $\begin{array}{l}\text { Near field communication (NFC) [88], IEC } 61158 \text { model, PROFIBUS and } \\
\text { PROFINET and distributed object model environment (DOME) [89], OPC-UA } \\
\text { (OLE process control unified architecture) gateway for IIoT [90] }\end{array}$ \\
\hline & Machine-to-machine (M2M) & $\begin{array}{l}\text { p-calculus [91], Open services for lifecycle collaboration (OSLC) [92], ontology- } \\
\text { based robotic interaction using Smart-M3 platform [93], OPC UA for M2M } \\
\text { communication [54] }\end{array}$ \\
\hline PC-HC interface & HMI & $\begin{array}{l}\text { Fault tree analysis (FTA) and "failure mode and effects analysis" (FMEA) [122], } \\
\text { wearable technology [120, 121], semantic web-based mobile interaction [49], } \\
\text { visual computing in HMI for intelligent maintenance system (IMS) [97], workflow } \\
\text { manager (WFM) [110] }\end{array}$ \\
\hline
\end{tabular}


different constituents of Industry 4.0 components, i.e., HC, $\mathrm{CC}, \mathrm{PC}$, and their interfaces.

Moreover, the following subsections will detail the link between used techniques and components.

\subsection{Techniques in HC}

Logistic learning factory (LLF) [51], work-based learning, and augmented reality (AR) $[52,54]$ are three key learning techniques to make worker capable of working in a newly introduced industrial environment. Moreover, contributions [51, 52, 54, 99] propose new architectures based on cyberphysical production (CPPS) formal modelization. Based on this, [50] defines an architecture of the system as a composition of existing or well-defined cyber-physical components and the connectors required to interconnect them.

A CPS for manufacturing in Industry 4.0 usually interfaces to humans and may be considered as a composition of subsystems. In spite of the failure of unmanned factory of the future (FoF), lean automation [57] achieved popularity due to its holistic nature. Further interaction with the human is focused in [55, 56]. Humancentered CPSs is far more complex than classical humanmachine interaction. As [52] detail, interaction leads to the construction of knowledge where participating entities belong to a symbolic, language-oriented system. Their interaction is mainly dependent on one entity's interpretation of another entity's behavior. However, this increased connectivity among humans and machine raises the need to go beyond the syntactic level of "speaking" the same language. Therefore, an article [49] proposes an approach for factory automation based on specific ontologies or semantic Web.

Human component (HC) has interfaces to cyber component (CC) through the user interface as well as to physical component (PC) through human-machine interface (HMI). For HC-CC interface, a reference architecture model for Industry 4.0 (RAMI 4.0) using SPARQL [95], mobile communication [49, 99], and web-based interface [98] have been introduced. Fault tree analysis (FTA) and "failure mode and effects analysis" (FMEA) [122], wearable technology [120, 121], semantic web-based mobile interaction [49], and visual computing in HMI for intelligent maintenance system (IMS) [97] have been used for HCPC interface techniques. After all, a central module of CPS-based architecture, described in [110], is the workflow manager (WFM). It is a scheduler, which provides the higher level-systems for production and receives the product requirements supplied by the operator to the humanmachine interface.

\subsection{Techniques in CC}

The "single source of truth," where data can be accumulated in a single storage, is one of the four enablers for data integration in collaborative production system [67]. In this connection, cloud-based data storage [58-60] may play an important role in Industry 4.0. In the cloud, Infrastructureas-a-Service (IaaS), Platform-as-a-Service (PaaS), and Software-as-a-Service (SaaS) [60, 68] are proposed as layered services. The service integration is addressed for federative cloud-based platform [58, 133]. On the other hand, system modeling language (SysML) (an extension of unified modeling language (UML)) and AutomationML are proposed [61] for data analysis and integration. The modeldriven software engineering (MDSE) methodology [65] is used in implementation of the sense-compute-control (SCC) applications [134]. Particle swarm optimization (PSO) [63] algorithm based on the heuristic method is proposed to recovery of the end-of-use products. Moreover, virtual engineering [63] has been proposed for the value chain management.

Taking dataflow and big data into account, a lot of data-driven approaches are proposed. Machine learning techniques like naive Bayes classifiers has been used to achieve data-driven self-predictive capabilities [62]. The articles [80] propose a model using bigdata and IoT where structural information about the plant is imported from the engineering chain and the temporal behavior. Based on this, [105] and [85] detail a cognitive layer such as ontology and knowledge management to increase CPS efficiency in the decision model. Multi-criteria decision-making framework [75, 135], direct web remoting (DWR) framework [82], and SEBoK and SQuaRE model [86] have been proposed as architecture. Nevertheless, multi-agent system (MAS) [72, 77-79, 83, 87] is considered as a widely addressed interactive approach.

Moreover, failure and repair management is an important module of industry automation. Intelligent ramp-up assistant [69], agent-based closed-loop repair process chain [70], and different data mining techniques [24] are used to address this issue.

In another side, CC-PC interface integrates cyber component to the physical component. In this connection, data acquisition is an essential part to retrieve data at the physical-to-cyber interface. Semantic modeling [83, 102, 104, 105] and SCADA [83] are used for data acquisition. On the other hand, hardware control becomes inevitable to achieve physical reconfiguration. Digital object memory (DOMe) [106], CIMory [107, 110], timestamp in communication [111], and RFID [24, 68] are 
important technologies to contain instant data for further decision-making.

\subsection{Techniques in PC}

Sensors and actuators are essential elements in an automated manufacturing and production scheduling. Built-in CPS device and its optimization for the different tasks are presented in [94].

Reconfiguration of the physical component is an inevitable module of Industry 4.0. This is responsible for adapting the machine to work in dynamic environment. Operator controller module (OCM) [112], CIMory and workflow manager (WFM) [107], robot [113, 114] utilization, SEFU/IFU [115], and web-socket messaging [117] are the techniques used for this purpose. However, this requires data acquisition into the cyber component for further decision. In the physical layer, a physical-to-cyber interface is responsible for this data transmission. DataMatrixHF or UHF[119] in industries 4.0 implements tagging technology to track manufactured parts in industrial automated manufacturing environments. This fed information to the cyber layer for efficient decision-making.

In physical component, communication among working devices is the key enabler to work collectively. Near field communication (NFC) [88], IEC 61158 model, PROFIBUS and PROFINET and distributed object model environment (DOME) [89], OPC-UA (OLE for process control, unified architecture) gateway [90] are used as the communication technologies.

To optimize sensor, actuator, and decision-making system, the articles [93] and [91] propose a new hardware with an objective to enable dynamics of reconfiguration and intelligent data management is driven by sensors. Open services for lifecycle collaboration (OSLC) [92] and OLE for process control unified architecture (OPC UA) plays an important role in $\mathrm{M} 2 \mathrm{M}$ communication.

Furthermore, PC-HC interface is important to take a human into the automation loop. Fault tree analysis (FTA) and "failure mode and effects analysis" (FMEA) [122], wearable technology [120, 121], semantic web-based mobile interaction [49], and visual computing in HMI for intelligent maintenance system (IMS) [97] are a few techniques for this purpose. After all, workflow manager (WFM) [110] plays an important role in HMI.

\section{Discussion}

The main technologies behind the revolutionary Industry 4.0 concept are CPS, IoT, and IoS. However, comprehensive understanding, clear relation, and boundaries of the technologies are the key to success in this domain. Therefore, we tried to make a comprehensive relation and boundaries among the different technologies (Fig. 1).

In this review article, we tried to identify the different essential components of "CPS for manufacturing in Industry 4.0" and their linking interfaces. We found interesting constituents in the major components, i.e., HC, CC, and PC. We have designed building blocks of Industry 4.0 with the components and their interfaces in Fig. 5.

We elaborated the challenges so far addressed by the different researchers of this domain in their contributions. Then different approaches were discussed to address the challenges.

In the last but not least, we collected the major techniques used in different levels (see Table 7) of CPS for Manufacturing in Industry 4.0. It would help researchers and entrepreneurs to choose their appropriate techniques in their ways to address CPS for manufacturing in Industry 4.0.

\section{Conclusions}

In summary, we have observed the challenges, approaches, and used state-of-the-art techniques of the CPS for manufacturing from various component perspectives to enable Industry 4.0 to develop effectively. After the unsuccessful mission of the unmanned factory of future $(\mathrm{FoF})$, we need a careful movement to incorporate anthropocentric cyber-physical systems (ACPS) to achieve the goal of cyberphysical production systems (CPPS), i.e., the manufacturing with Industry 4.0. We need an appropriate integration of the major components: $\mathrm{HC}, \mathrm{CC}$, and PC. In spite of the emergence of many buzz words along with the diversified approaches and techniques, we need a good trade-off in the selection of appropriate techniques for constituents of components to achieve seamless operations in a dynamic environment with flexible customer requirements. Moreover, The dynamic and reconfiguration capability of Industry 4.0 requires a quick holistic learning approach for the worker, easy user interface, suitable human-machine interaction (HMI), data acquisition, storage and data management, appropriate service architecture, reconfigurable failure and repair management, effective machine to machine communication, secure and seamless communication technology, and the last but not least effective interfaces between components.

Author contributions All authors contributed to the study conception and design. Material preparation, data collection, and analysis were performed by Baudouin Dafflon, Nejib Moalla, and Yacine Ouzrout. The first draft of the manuscript was written by the three authors and all authors commented on previous versions of the manuscript. All authors read and approved the final manuscript. 
Data availability The datasets used and/or analyzed during the current study are available from the corresponding author on reasonable request.

\section{Compliance with ethical standards}

Competing interests The authors declare that they have no conflict of interest.

\section{Consent to participate NA}

\section{Consent to publish NA}

Open Access This article is licensed under a Creative Commons Attribution 4.0 International License, which permits use, sharing, adaptation, distribution and reproduction in any medium or format, as long as you give appropriate credit to the original author(s) and the source, provide a link to the Creative Commons licence, and indicate if changes were made. The images or other third party material in this article are included in the article's Creative Commons licence, unless indicated otherwise in a credit line to the material. If material is not included in the article's Creative Commons licence and your intended use is not permitted by statutory regulation or exceeds the permitted use, you will need to obtain permission directly from the copyright holder. To view a copy of this licence, visit http:// creativecommonshorg/licenses/by/4.0/.

\section{References}

1. Evans PC, Annunziata M (2012) Industrial internet: pushing the boundaries. General Electric Reports 488-508

2. Iansiti M, Lakhani KR (2014) Digital ubiquity: how connections, sensors, and data are revolutionizing business (digest summary). Harv Bus Rev 92(11):91-99

3. Kagermann Henning, Lukas Wolf-Dieter, Wahlster Wolfgang (2011) Industrie 4.0: Mit dem internet der dinge auf dem weg zur 4. industriellen revolution. VDI nachrichten 13:2011

4. Kagermann H, Wahlster W, Helbig J (2013) Umsetzungsempfehlungen für das zukunftsprojekt industrie 4.0. Abschlussbericht des Arbeitskreises Industrie 4:5

5. Hermann M, Pentek T, Otto B (2015) Design principles for industry 4.0 scenarios. http://www.snom. mb.tu-dortmund.de/cms/de/forschung/Arbeitsberichte/

Design-Principles-for-Industrie-4_0-Scenarios.pdf. [Online; Accessed 11 May 2016]

6. Kagermann H, Helbig J, Hellinger A, Wahlster W (2013) Recommendations for implementing the strategic initiative INDUSTRIE 4.0: securing the future of german manufacturing industry; final report of the industrie 4.0 working group forschungsunion

7. Liu M, Ma J, Lin L, Ge M, Wang Q, Liu C (2014) Intelligent assembly system for mechanical products and key technology based on internet of things. J Intell Manuf 1-29

8. Sauter T, Soucek S, Kastner W, Dietrich D (2011) The evolution of factory and building automation. IEEE Ind Electron Mag 3(5):35-48

9. Kagermann H (2013) Recommendations for implementing the strategic initiative industrie 4.0

10. Buergy C, Kenn H (2013) Wearable systems for industrial augmented reality applications. In: Proceedings of the 2013 ACM conference on Pervasive and ubiquitous computing adjunct publication. ACM, pp 1463-1466
11. Ziegler J, Pfeffer J, Urbas L (2011) A mobile system for industrial maintenance support based on embodied interaction. In: Proceedings of the fifth international conference on Tangible, embedded, and embodied interaction. ACM, pp 181-188

12. Drath R, Lüder A, Peschke J, Hundt L (2008) Automationml-the glue for seamless automation engineering. In: Emerging technologies and factory automation, 2008. ETFA IEEE international conference on. IEEE, p 2008

13. Ferber J (1999) Multi-agent systems: an introduction to distributed artificial intelligence, vol. 1 Addison-Wesley Reading

14. Wooldridge M (2009) An introduction to multiagent systems. Wiley, New Jersey

15. Gorbach G, Nick R (2002) Collaborative manufacturing management strategies White paper. ARC Advisory Group, Germany, p 56

16. Leitão P, Colombo AW, Karnouskos S (2016) Industrial automation based on cyber-physical systems technologies: prototype implementations and challenges. Comput Indust 81:11-25

17. Colombo AW, Karnouskos S (2009) Towards the factory of the future: a service-oriented cross-layer infrastructure. ICT Shaping the world: A Scientific View. European Telecommunications Standards Institute (ETSI), vol 65. Wiley, New Jersey, p 81

18. Colombo AW, Bangemann T, Karnouskos S, Delsing J, Stluka P, Harrison R, Jammes F, Lastra JL et al (2014) Industrial cloud-based cyber-physical systems. The Imc-aesop Approach 22:4-5

19. Cristalli C, Foehr M, Jager T, Leitao P, Paone N, Castellini P, Turrin C, Schjolberg I (2013) Integration of process and quality control using multi-agent technology. In: Industrial electronics (ISIE) IEEE international symposium on. IEEE, p 2013

20. Marin CA, Monch L, Leitao P, Vrba P, Kazanskaia D, Chepegin V, Liu L, Mehandjiev N (2013) A conceptual architecture based on intelligent services for manufacturing support systems. In: Systems man and cybernetics (SMC) IEEE international conference on. IEEE, p 2013

21. Lee EA (2006) Cyber-physical systems-are computing foundations adequate. In: Position paper for NSF workshop on cyberphysical systems: research motivation, techniques and roadmap, vol 2. Citeseer, pp 1-9

22. Lee EA (2008) Cyber physical systems: design challenges. In: Object oriented real-time distributed computing (ISORC), 2008 11th IEEE international symposium on. IEEE, pp 363369

23. Rajkumar RR, Lee I, Sha L, Stankovic J (2010) Cyber-physical systems: the next computing revolution. In: Proceedings of the 47th design automation conference. ACM, pp 731-736

24. Wang K (2016) Intelligent predictive maintenance (ipdm) system-industry 4.0 scenario. WIT Trans Eng Sci 113:259268

25. Lee EA (2010) Cps foundations. In: Proceedings of the 47th design automation conference. ACM, pp 737-742

26. Babiceanu RF, Seker R (2015) Manufacturing cyber-physical systems enabled by complex event processing and big data environments: a framework for development. In: Service orientation in Holonic and multi-agent manufacturing. Springer, pp $165-173$

27. Baheti R, Gill H (2011) Cyber-physical systems. Impact Control Technol 12:161-166

28. Ishaq I, Carels D, Teklemariam GK, Hoebeke J, Van den Abeele F, De Poorter E, Moerman I, Demeester P (2013) Ietf standardization in the field of the internet of things (iot): a survey. J Sensor Actuat Netw 2(2):235-287

29. Porter ME, Heppelmann JE (2014) How smart, connected products are transforming competition. Harv Bus Rev 92(11):6488 
30. Vermesan O, Friess P (2014) Internet of Things-from research and innovation to Market Deployment. River Publishers, Denmark

31. Zhou L, Chong AYL, Ngai EWT et al (2015) Supply chain management in the era of the internet of things. Int J Prod Econ 159:1-3

32. Atzori L, Iera A, Morabito G (2010) The internet of things: a survey. Comput Netw 54(15):2787-2805

33. Roman R, Zhou J, Lopez J (2013) On the features and challenges of security and privacy in distributed internet of things. Comput Netw 57(10):2266-2279

34. Industrie 4.0 Working Group et al (2013) Securing the future of german manufacturing industry: recommendations for implementing the strategic initiative industrie 4.0 Federal Ministry of Education and Research of German

35. Gubbi J, Buyya R, Marusic S, Palaniswami M (2013) Internet of things (iot): a vision, architectural elements, and future directions. Futur Gener Comput Syst 29(7):1645-1660

36. Cardoso J, Voigt K, Winkler M (2008) Service engineering for the internet of services. In: Enterprise information systems. Springer, pp 15-27

37. Picard A, Anderl R, Schützer K, de Assis Moura AÁ (2013) Linked product and process monitoring in smart factories based on federative factory data management. In: ASME 2013 international mechanical engineering congress and exposition, pp V011T06A002-V011T06A002. American society of mechanical engineers

38. Steinmetz C, Christ A, Anderl R et al (2014) Data management based on internet technology using restful web services. In: Proceedings of the 10th international workshop on integrated design engineering, pp 061-072

39. Zamfirescu C-B, Pirvu B-C, Schlick J, Zuehlke D (2013) Preliminary insides for an anthropocentric cyber-physical reference architecture of the smart factory. Stud Inform Control 22(3):269278

40. Erol S, Schumacher A, Sihn W (2016) Strategic guidance towards industry $4.0-\mathrm{a}$ three-stage process model. Int Conf Competit Manufact 9:495-501

41. Christiansen L, Fay A, Opgenoorth B, Neidig J (2011) Improved diagnosis by combining structural process knowledge. In: Emerging Technologies \& Factory Automation (ETFA), 2011 IEEE 16th Conference on. IEEE, pp 1-8

42. Isermann R (2005) Model-based fault-detection and diagnosisstatus and applications. Annual Rev Control 29(1):71-85

43. de Kleer J, Janssen B, Bobrow DG, Kurtoglu T, Saha B, Moore NR, Sutharshana S (2013) Fault augmented modelica models. In: The 24th international workshop on principles of diagnosis, pp 71-78

44. Klar D, Huhn M, Grühser J (2011) Symptom propagation and transformation analysis: a pragmatic model for systemlevel diagnosis of large automation systems. In: Emerging technologies \& factory automation (ETFA), 2011 IEEE 16th conference on. IEEE, pp 1-9

45. Struss P, Ertl B (2009) Diagnosis of bottling plants-first success and challenges. In: 20th international workshop on principles of diagnosis. Citeseer, pp 83-90

46. Windmann S, Jiao S, Niggemann O, Borcherding H (2013) A stochastic method for the detection of anomalous energy consumption in hybrid industrial systems. In: Industrial Informatics (INDIN), 2013 11th IEEE international conference on. IEEE, pp 194-199

47. Aghassi S, Bauhoff F, Brecher C, Fuchs S, Jeschke S, Jooß C, Kozielski S, Orilski S, Richert A, Roderburg A et al (2011) Integrative produktionstechnik für hochlohnländer. In: Integrative Produktionstechnik für Hochlohnländer. Springer, pp 17-81
48. Knop C (2015) Das unbekannte internet der dinge. Frankfurter Allgemeine Zeitung 2015:26

49. Pirvu B-C, Zamfirescu C-B, Gorecky D (2016) Engineering insights from an anthropocentric cyber-physical system: a case study for an assembly station. Mechatronics 34:147-159

50. Thramboulidis K (2015) A cyber-physical system-based approach for industrial automation systems. Comput Ind 72:92102

51. Hummel V, Hyra K, Ranz F, Schuhmacher J (2015) Competence development for the holistic design of collaborative work systems in the logistics learning factory. Procedia CIRP 32:7681

52. Quint F, Sebastian K, Gorecky D (2015) A mixed-reality learning environment. Procedia Comput Sci 75:43-48

53. Schuh G, Gartzen T, Rodenhauser T, Marks A (2015) Promoting work-based learning through industry 4.0. Procedia CIRP 32:8287

54. Speicher M, Tenhaft K, Heinen S, Handorf H (2015) Enabling industry 4.0 with holobuilder. In: Cunningham DW, Hofstedt P, Meer K, Schmitt I (eds) INFORMATIK 2015, vol 246, Germany, pp 1561-1575

55. Gradišar D, Glavan M, Strmčnik S, Mušič G (2015) Proopter: an advanced platform for production analysis and optimization. Comput Ind 70(C):102-115

56. Hadorn B, Courant M, Hirsbrunner B (2015) Holistic system modelling for cyber physical systems. In: The 6th International Multi-Conference on Complexity, Informatics and Cybernetics (IMCIC 2015), Accepted paper

57. Kolberg D, Zühlke D (2015) Lean automation enabled by industry 4.0 technologies. IFAC-PapersOnLine 48(3):1870-1875

58. Holtewert P, Wutzke R, Seidelmann J, Bauernhansl T (2013) Virtual fort knox federative, secure and cloud-based platform for manufacturing. Procedia CIRP 7:527-532

59. Shu Z, Wan J, Zhang D, Li D (2015) Cloud-integrated cyberphysical systems for complex industrial applications. Mob Netw Appl 1-14

60. Yue X, Cai H, Yan H, Zou C, Zhou K (2015) Cloud-assisted industrial cyber-physical systems: an insight. Microprocess Microsyst 39(8):1262-1270

61. Backhaus J, Reinhart G (2015) Digital description of products, processes and resources for task-oriented programming of assembly systems. J Intell Manuf 1-14

62. Diaz J, Bielza C, Ocaña JL, Larrañaga P (2016) Development of a cyber-physical system based on selective gaussian naïve bayes model for a self-predict laser surface heat treatment process control. In: Machine learning for Cyber physical systems. Springer, pp 1-8

63. Fang C, Liu X, Pardalos PM, Pei J (2015) Optimization for a three-stage production system in the internet of things: procurement, production and product recovery, and acquisition. Int J Adv Manufact Technol 1-22

64. Mikusz M (2014) Towards an understanding of cyber-physical systems as industrial software-product-service systems. Procedia CIRP 16:385-389

65. Moin AH (2014) Domain specific modeling (dsm) as a service for the internet of things and services. In: Internet of things. User-Centric IoT. Springer, pp 347-354

66. Sadok DFH, Gomes LL, Eisenhauer M, Kelner J (2015) A middleware for industry. Comput Ind 71:58-76

67. Schuh G, Reuter C, Hauptvogel A (2015) Increasing collaboration productivity for sustainable production systems. Procedia CIRP 29:191-196

68. Wang S, Wan J, Li D, Zhang C (2016) Implementing smart factory of industrie 4.0: an outlook. Int J Distribut Sensor Netw 12(1):3159805 
69. Bauer W, Ganschar O, Pokorni B, Schlund S (2014) Concept of a failures management assistance system for the reaction on unforeseeable events during the ramp-up. Procedia CIRP $25: 420-425$

70. Spöcker G, Schreiner T, Huwer T, Arntz K (2016) Programming of adaptive repair process chains using repair features and function blocks. J Comput Design Eng 3(1):53-62

71. Zhang Z, Liu G, Jiang Z, Chen Y (2015) A cloud-based framework for lean maintenance, repair, and overhaul of complex equipment. J Manuf Sci Eng 137(4):11

72. Ang JH (2015) Forum discussion: design knowledge capture, optimisation \& automation to advance industry 4.0. In: Automation and Computing (ICAC), 2015 21st international conference on. IEEE, pp 1-1

73. Chen J, Yang J, Zhou H, Xiang H, Zhu Z, Li Y, Lee C$\mathrm{H}$, Guangda X (2015) Cps modeling of cnc machine tool work processes using an instruction-domain based approach. Engineering 1(2):247-260

74. Cheng L, Wang T, Hong X, Wang Z, Wang J, Liu J (2015) A study on the architecture of manufacturing internet of things. Int J Modell Identific Control 23(1):8-23

75. Colledani M, Tolio T, Fischer A, Iung B, Lanza G, Schmitt $\mathrm{R}$, Vancza J (2014) Design and management of manufacturing systems for production quality. CIRP Annals-Manufact Technol 63(2):773-796

76. Himmler F (2015) Function based engineering with automationml-towards better standardization and seamless process integration in plant engineering. In: Wirtschaftsinformatik, pp 16-30

77. Jain S, Lechevalier D, Woo J, Shin S-J (2015) Towards a virtual factory prototype. In: 2015 Winter Simulation Conference (WSC). IEEE, pp 2207-2218

78. Leitão P, Rodrigues N, Barbosa J, Turrin C, Pagani A (2015) Intelligent products: the grace experience. Control Eng Pract 42:95-105

79. Leitao P, Rodrigues N, Turrin C, Pagani A (2015) Multiagent system integrating process and quality control in a factory producing laundry washing machines. Indust Inform IEEE Trans 11(4):879-886

80. Niggemann O, Biswas G, Kinnebrew JS, Khorasgani H, Volgmann S, Bunte A (2015) Data-driven monitoring of cyberphysical systems leveraging on big data and the internet-ofthings for diagnosis and control. In: DX@ Safeprocess, pp 185192

81. Pisching MA, Junqueira F, dos Santos Filho DJ, Miyagi PE (2015) An architecture for organizing and locating services to the industry 4.0. In: $23 \mathrm{rd} \mathrm{ABCM}$ international congress of mechanical engineering, COBEM-2015. ABCM, pp 1-8

82. Polonia PV, Melgarejo LFB, de Queiroz MH (2015) A resource oriented architecture for web-integrated scada applications. In: Factory Communication Systems (WFCS) 2015 IEEE World Conference on. IEEE, pp 1-8

83. Schoeler T. (2014) The sepia cyber-physical production control system. J Electrotechnic Comput Syst 89(13):197-202

84. Thoben K-D, Pöppelbuß J, Wellsandt S, Teucke M, Werthmann D (2014) Considerations on a lifecycle model for cyber-physical system platforms. In: Advances in production management systems. Innovative and knowledge-based production management in a global-local world. Springer, pp 85-92

85. Toro C, Barandiaran I, Posada J (2015) A perspective on knowledge based and intelligent systems implementation in industrie 4.0. Procedia Comput Sci 60:362-370

86. Vidoni MC, Vecchietti AR (2015) A systemic approach to define and characterize advanced planning systems (aps). Comput Ind Eng 90(C):326-338
87. Wang S, Wan J, Zhang D, Di L, Zhang C (2016) Towards smart factory for industry 4.0: a self-organized multi-agent system with big data based feedback and coordination. Comput Netw 101:158-168

88. Lesjak C, Ruprechter T, Haid J, Bock H, module EB (2014) System concept for local and remote industrial embedded system identification. In: Emerging Technology and Factory Automation (ETFA) A secure hardware IEEE. IEEE, p 2014

89. Riedl M, Zipper H, Meier M, Diedrich C (2014) Cyber-physical systems alter automation architectures. Annu Rev Control 38(1):123-133

90. Ulltveit-Moe N, Nergaard H, Erdödi L, Gjøsæter T, Kolstad E, Berg P (2016) Secure information sharing in an industrial internet of things. arXiv:1601.04301

91. Deng P, Ren G, Yuan W, Chen F, Hua Q (2015) An integrated framework of formal methods for interaction behaviors among industrial equipments. Microprocess Microsyst 39(8):1296-1304

92. Kaiser C, Herbst B (2015) Smart engineering for smart factories: How oslc could enable plug \& play tool integration Mensch und Computer 2015-Workshopband

93. Kashevnik A, Teslya N, Padun B, Kipriyanov K, Arckhipov V (2015) Industrial cyber-physical system for lenses assembly: configuration workstation scenario. In: Open innovations association (FRUCT), 2015 17th conference of. IEEE, pp 6267

94. Berger C, Hees A, Braunreuther S, Reinhart G (2016) Characterization of cyber-physical sensor systems. Procedia CIRP 41:638-643

95. Grangel-Gonz I, Halilaj L, Coskun G, Auer S, Collarana D, Hoffmeister $M$ et al (2016) Towards a semantic administrative shell for industry 4.0 components. In: 2016 IEEE tenth international conference on semantic computing (ICSC). IEEE, pp 230-237

96. Kannengiesser U, Neubauer M, Di Francescomarino C, Dragoni M, Ghidini C, Heininger R (2015) Worker-driven improvement of processes in smart factories 239-244

97. Posada J, Toro C, Barandiaran I, Oyarzun D, Stricker D, De Amicis R, Pinto EB, Eisert P, Dollner J, Vallarino I (2015) Visual computing as a key enabling technology for industrie 4.0 and industrial internet. Comput Graphics Appl IEEE 35(2):26-40

98. Rudtsch V, Gausemeier J, Gesing J, Mittag T, Peter S (2014) Pattern-based business model development for cyber-physical production systems. Procedia CIRP 25:313-319

99. Spath D, Gerlach S, Hämmerle M, Schlund S, Strölin T (2013) Cyber-physical system for self-organised and flexible labour utilisation. Personnel 50:22

100. Thramboulidis K, Christoulakis F (2015) Uml4iot-a uml profile to exploit iot in cyber-physical manufacturing systems. arXiv: 1512.04894

101. Cai H, Zhang Y, Yan H, Shen F, Zhou K, Zhang C (2016) A delay-aware wireless sensor network routing protocol for industrial applications. Mob Netw Appl 1-11

102. Cheng C-H, Guelfirat T, Messinger C, Schmitt JO, Schnelte M, Weber P (2015) Semantic degrees for industrie 4.0 engineering: deciding on the degree of semantic formalization to select appropriate technologies 1010-1013

103. Gölzer P, Cato P, Amberg M (2015) Data processing requirements of industry 4.0-use cases for big data applications. Data Processing

104. Sarraipa J, de Beca MF, Marques-Lucena C, Jardim-Goncalves $\mathrm{R}$ et al (2014) Knowledge management support in sensing enterprises establishment. In: World Congress, vol 19, pp 839844

105. Zandera S, Huab Y (2016) Utilizing ontological classification systems and reasoning for cyber-physical systems. In: 
The second Karlsruhe Service Summit (KSS) Research Workshop Karlsruhe Service Research institute/KIT, February 2526

106. Aruväli T, Maass W, Otto T (2014) Digital object memory based monitoring solutions in manufacturing processes. Procedia Eng 69:449-458

107. Friedrich J, Scheifele S, Verl A, Lechler A (2015) Flexible and modular control and manufacturing system. Procedia CIRP $33: 115-120$

108. Niggemann O, Henning S, Schriegel S, Otto J, Anis A (2015) Models for adaptable automation software an overview of plugand-produce in industrial automation. In: The 11th Dagstuhl Workshop Modellbasierte Entwicklung eingebetteter Systeme (MBEES), Dagstuhl, p 73

109. Rabe M, Clausen U (2015) Simulation-based optimisation in industry 4.0. In: ASIM Dedicated Conferences on Simulation in Production and Logistics, September 23-25, Dortmund

110. Scheifele S, Friedrich J, Lechler A, Verl A (2014) Flexible, selfconfiguring control system for a modular production system. Procedia Technol 15:398-405

111. Vyatkin V, Pang C, Tripakis S (2015) Towards cyber-physical agnosticism by enhancing iec 61499 with ptides model of computations. In: IECON 2015-41st annual conference of the IEEE industrial electronics society. IEEE, pp 1970-1975

112. Dumitrescu R, Anacker H, Gausemeier J (2013) Design framework for the integration of cognitive functions into intelligent technical systems. Prod Eng 7(1):111-121

113. Hess P, Wagner M (2015) New developments in industrial robot programming. In: Athens: ATINER'S Conference Paper Series, volume No: IND2015-1640

114. Michniewicz J, Reinhart G (2014) Cyber-physical roboticsautomated analysis, programming and configuration of robot cells based on cyber-physical-systems. Procedia Technol 15:566-575

115. Mönks U, Trsek H, Dürkop L, Geneiß V, Lohweg V (2016) Towards distributed intelligent sensor and information fusion. Mechatronics 34:63-71

116. Niggemann O, Windmann S, Volgmann S, Bunte A, Stein B (2014) Using learned models for the root cause analysis of cyber-physical production systems. In: The 25th International Workshop on the Principles of Diagnosis (DX), Graz, Austria. Konferenzbeitrag, Elektronische Publikation

117. Schmitt M, Orfgen M, Zühlke D (2015) Dynamic reconfiguration of intelligent field devices by using modular software applications. IFAC-PapersOnLine 48(3):561-566

118. Dosch S, Spohrer A, Fleischer J (2015) Reduced commissioning time of components in machine tools through electronic data transmission. Procedia CIRP 29:311-316

119. Velandia DMS, Kaur N, Whittow WG, Conway PP, West AA (2016) Towards industrial internet of things: crankshaft monitoring, traceability and tracking using rfid. Robot Comput Integr Manuf 41:66-77

120. Hao Y, Helo P (2017) The role of wearable devices in meeting the needs of cloud manufacturing: a case study. Robot Comput Integr Manuf 45:168-179
121. Paelke V, Röcker C, Koch N, Flatt H, Büttner S (2015) User interfaces for cyber-physical systems. at-Automatisierungstechnik 63(10):833-843

122. Anacker H, Dumitrescu R, Gausemeier J, Iwanek P, Schierbaum $\mathrm{T}$ (2014) Methodology for the identification of potentials for the integration of self-optimization in mechatronic systems. Procedia Technol 15:17-26

123. Rosenberg E, Haeusler MH, Araullo R, Gardner N (2015) Smart architecture-bots and industry 4.0 principles for architecture. In: The 33rd eCAADe Conference on Real Time, Vienna University of Technology, Vienna, Austria, 16-18 September, vol 2. eCAADe, pp 251-259

124. Yao X, Zhou J, Lin Y, Li Y, Hongnian Y, Liu Y (2019) Smart manufacturing based on cyber-physical systems and beyond. J Intell Manuf 30(8):2805-2817

125. Tao F, Qi Q, Wang L, Nee AYC (2019) Digital twins and cyberphysical systems toward smart manufacturing and industry 4.0: correlation and comparison. Engineering 5(4):653-661

126. Haupert J, Klinge X, Blocher A (2017) Cps-based manufacturing with semantic object memories and service orchestration for industrie 4.0 applications. In: Industrial internet of things. Springer, pp 203-229

127. Adamson G, Wang L, Moore P (2017) Feature-based control and information framework for adaptive and distributed manufacturing in cyber physical systems. J Manufact Syst 43:305-315

128. Liu Y, Wang L, Xi VW, Xun X, Jiang P (2019) Cloud manufacturing: Key issues and future perspectives. Int J Comput Integr Manuf 32(9):858-874

129. Li J, Tao F, Cheng Y, Zhao L (2015) Big data in product lifecycle management. Int J Adv Manufact Technol 81(1-4):667-684

130. Frontoni E, Loncarski J, Pierdicca R, Bernardini M, Sasso M (2018) Cyber physical systems for industry 4.0: towards real time virtual reality in smart manufacturing. In: International conference on augmented reality, virtual reality and computer graphics. Springer, pp 422-434

131. Guo Z, Zhang Y, Zhao X, Song X (2020) Cps-based self-adaptive collaborative control for smart production-logistics systems. IEEE Trans Cybern

132. Harper KE, de Gooijer T, Smiley K (2016) Composable industrial internet applications for tiered architectures. arXiv: 1602.05163

133. Wang L, Ji W (2018) Cloud enabled cps and big data in manufacturing. In: International conference on the industry 4.0 model for advanced manufacturing. Springer, pp 265-292

134. Patel P, Morin B, Chaudhary S (2014) A model-driven development framework for developing sense-compute-control applications. In: Proceedings of the 1st international workshop on modern software engineering methods for industrial automation. ACM, pp 52-61

135. Zhang Y, Guo Z, Lv J, Liu Y (2018) A framework for smart production-logistics systems based on cps and industrial iot. IEEE Trans Indust Inform 14(9):4019-4032

Publisher's note Springer Nature remains neutral with regard to jurisdictional claims in published maps and institutional affiliations. 